\title{
The near-patient test FlexSure had low sensitivity and high specificity for detecting Helicobacter pylori infection
}

Duggan AE, Elliott C, Logan RF Testing for Helicobacter pylori infection: validation and diagnostic yield of a near patient test in primary care. BMJ 1999 Nov 6:319:1236-9.

QUESTION: In adults who have symptoms of dyspepsia and consult a general practitioner, is a near patient test (FlexSure) accurate for detecting Helicobacter pylori infection?

\section{Design}

Blinded comparison of a near patient test with an enzyme linked immunosorbent assay (ELISA) within a randomised controlled trial of 4 management strategies for dyspepsia.

\section{Setting}

43 general practices in Nottinghamshire, England.

\section{Participants}

762 adults who were 18-73 years of age (mean age $42 \mathrm{y}$ ) and had symptoms of dyspepsia of sufficient severity to justify empiric treatment with $\mathrm{H}_{2}$-antagonists or proton pump inhibitors. Exclusion criteria were symptoms consistent with malignant tumors, a history of peptic ulcer or reflux esophagitis, investigation for dyspepsia in the previous 5 years, treatment in the previous 6 months with non-steroidal anti-inflammatory drugs or $\mathrm{H}$ pylori eradication treatment, or $\geq 3$ prescriptions in the previous 6 months for acid suppression treatment. 394 patients in 39 general practices were in the 2 management groups that received the FlexSure and ELISA tests.

Description of test and diagnostic standard After randomisation, a $7 \mathrm{ml}$ blood sample was taken, and the physician or practice nurse followed the manufacturer's instructions for testing serum from the clotted sample with FlexSure (SmithKline Diagnostics; San Jose, CA, USA). The diagnostic standard was an ELISA (HMCAP, Enteric Products; Westbury, NY, USA).

\section{Main outcome measures}

Sensitivity and specificity for detecting $H$ pylor $i$ infection.

\section{Main results}

Results were available for 375 patients (9 patients had indeterminate ELISA results, 5 had invalid FlexSure results, and 8 had no serum available). $36 \%$ of patients had $H$ pylori infection. The table shows the sensitivity, specificity, and likelihood ratios.

FlexSure test characteristics for detecting Helicobacter pylori infection*

\begin{tabular}{llll}
\hline Sensitivity $(95 \%$ CI) & Specificity (CI) & +LR & -LR \\
\hline $67 \%(59$ to 75$)$ & $98 \%(95$ to 99$)$ & 32.4 & 0.3 \\
\hline
\end{tabular}

*Abbreviations defined in glossary; LRs calculated from data in article.

\section{Conclusion}

In adults who have symptoms of dyspepsia and consult a general practitioner, the near test FlexSure had low sensitivity and high specificity for detecting Helicobacter pylori infection.

\section{COMMENTARY}

Dyspeptic patients most likely to benefit from treatment are those with $H$ pylori associated peptic ulcer disease. Determining who has a peptic ulcer generally requires endoscopy, which is a minimally invasive but relatively expensive diagnostic test. One management algorithm designed to decrease the use of endoscopy in dyspeptic patients involves testing for $H$ pylori, treating those who are positive, and doing endoscopy in those who remain symptomatic. This test and treat strategy assumes that patients with $\mathrm{H}$ pylori and peptic ulcer disease are usually cured (and thus spared endoscopy) and that patients with $H$ pylori and non-ulcer dyspepsia will at least not be harmed by antimicrobial treatment. Such a strategy values highly sensitive diagnostic tests for $H$ pylori, thereby maximising the number of patients with peptic ulcer who have treatment. The standard laboratory ELISA has long been the favored screening test for $H$ pylori. Recently, more convenient in office serological or whole blood tests have become popular.

In the study by Duggan et al, the accuracy of 1 such serologic test (FlexSure) was assessed using a laboratory ELISA as the diagnostic standard. The in office test had excellent specificity (98\%) but a sensitivity of only $67 \%$, which means that one third of patients infected with $H$ pylori and a proportionate number of those with peptic ulcer would be missed. The authors conclude that tests with such poor sensitivity should not be used for the test and treat strategy. An alternate approach exists, however. Given its high specificity, the in office test could be used to rapidly and reliably diagnose two thirds of infected patients; the more sensitive laboratory ELISA could be reserved for those with negative results. However, the cost effectiveness of this strategy would be highly dependent on the relative costs of the tests (the in office test would have to be much less expensive than the ELISA) and on the prevalence of $H$ pylori in the population (the fewer people infected, the larger the number who would need a second test). All of these factors should be considered before an in office test is used for the test and treat strategy.

Walter L Peterson, MD Veterans Affairs Medical Center Dallas, Texas, USA
Sources of funding: NHS

Primary/Secondary Interface RED

Programme; Trent Region RED Wyeth-Lederle;Abbott Laboratories. Near patient tests and ELISAs were provided by SmithKline Diagnostics.

For correspondence: Dr R F Logan, Divisions of Public Health and Epidemiology and Gastroenterology, University of Nottingham, Nottingham NG7 2UH, UK. Fax $+44(0) 1159709316$. 